
\title{
28 Research Square \\ Unique Chemical Parameters and Microbial Activity Lead to Increased Archaeological Preservation within Vindolanda, UK.
}

C. HOrr

Teesside University

R Williams

Teesside University

H Halldórsdóttir

Teesside University

A Birley

Vindolanda Trust

E Greene

University of Western Ontario

A Nelson

Northumbria University

T.K Ralebitso-Senior

Liverpool John Moores University

G Taylor ( $\boldsymbol{Q}$ g.taylor@tees.ac.uk)

Teesside University

\section{Research Article}

Keywords: Vindolanda, Anaerobic, Amplicon Sequencing, Vivianite

Posted Date: March 10th, 2021

DOI: https://doi.org/10.21203/rs.3.rs-244364/v1

License: (1) (1) This work is licensed under a Creative Commons Attribution 4.0 International License.

Read Full License

Version of Record: A version of this preprint was published at Scientific Reports on August 4th, 2021. See the published version at https://doi.org/10.1038/s41598-021-94853-7. 


\section{Abstract}

Waterlogged burial conditions impact upon artefact preservation. One major determinant of preservation is presence and behaviour of microorganisms, however, unravelling the mechanisms is challenging. In this study, we analysed elemental composition, bacterial diversity and community structure from excavation trenches at the Roman Site of Vindolanda, Northumberland, UK, using pXRF and 16s rRNA gene amplicon sequencing. Excavation trenches provide layers which can be classed as phosphorus sinks and which are strongly linked to the abundance of vivanite. The results indicated that microbial communities were dominant in Firmicutes, Bacteroidetes and Proteobacteria at a phylum level. Samples which also had visible vivianite presence showed that there were marked increases in Methylophilus. Methylophilus might be associated with favourable preservation in these anaerobic conditions. More research is needed to clearly link the presence of Methylophilus with vivianite production. The study emphasises the need for further integration of chemical and microbiome approaches, especially in good preservation areas, to explore microbial and chemical degradation mechanisms.

\section{Introduction}

Vindolanda, a Roman auxiliary fort situated south of Hadrian's Wall near Bardon Mill, Northumberland UK, is a site known for its excellent preservation of leather and wooden artefacts ${ }^{1}$. This is typified by the writing tablets showing the correspondence of Julius Verecundus, Prefect of the First Cohort of Tungrians, dated to between 1st and 2nd centuries; an extensive assemblage of leather artefacts; and the discovery of the oldest Roman boxing gloves c.a. 120 AD. The fort is situated upon the Alston formation, which is calcium carbonate sedimentary bedrock, overlaid by loamy and clayey soils. However, this alone does not explain the exceptional level of artefact preservation ${ }^{1}$. Between Roman occupation periods, wooden and stone buildings were destroyed, sealed with thick layers of clays and then re-built upon, forming layers in which oxygen was excluded from the decomposing material underneath. This lack of oxygen led to the formation of anaerobic layers which are ideal preservation environments ${ }^{2}$ and created areas of waterlogging on top of dense clay layers.

Waterlogged environments have unique and complex hydrological chemistry, hence they are often too complex to determine individual indicators of good presevation ${ }^{3}$. A general lack of understanding of waterlogged environments has led English Heritage to adopt a reburial policy for in-situ preservation as is typified by the Rose and Globe Theatres in London ${ }^{4}$. Preservation indicators in waterlogged environments can include and be influenced by i) redox reactions, such as $\mathrm{Fe}^{3+}$ reducing to $\mathrm{Fe}^{2+}$, and formations of chemical complexes like vivianite through combination of $\mathrm{Fe}^{3+}$ and phosphate ${ }^{2}$, ii) microbiological species, such as decreasing abundance of Proteobacteria, Actinobacteria and Firmicutes, iii) hydrological indicators, such as acidity ( $\mathrm{pH}$ values), conductivity and oxidation-reduction potential, iv) the decomposition material of surrounding highly organic matter, including those rich in phosphates ${ }^{3}$. 
Redox reactions are one of the most important and visually impactful processes present at Vindolanda. Chemically vivianite $\left(\mathrm{Fe}_{3}\left(\mathrm{PO}_{4}\right)_{2} \cdot 8 \mathrm{H}_{2} \mathrm{O}\right)$ can form, when there is an availability of iron and phosphorus in the soil, lack of oxygen, low sulphur content and low pH values ${ }^{2,5,6}$. The phosphorus released from the decaying organic matter, such as floor material, animal faeces and plants is retained, through sorption to iron oxides and as such vivianite acts as a phosphorus sink. Upon excavation and exposure to oxygen, $\mathrm{Fe}^{3+}$ is converted to $\mathrm{Fe}^{2+}$, which produces the unique blue colouration of vivianite ${ }^{2}$. Interestingly, vivianite is associated with other instances of good preservation including that of human remains: For example human DNA of increased quality can be extracted from samples located within the Brisbane burial grounds from underneath vivianite crusts ${ }^{5}$. The formation of vivianite is also thought to be microbially mediated with studies showing a range of microorganisms capable of producing the substance in anaerobic culture when exposed to the correct conditions ${ }^{6-8}$. Thus, despite vivianite acting as a visible preservation indicator, the exact chemical and microbiological formation, production and generation mechanisms are not completely understood.

Microorganisms play a key role in decomposition, with above ground artefacts degraded by a range of bacteria, fungi and insects relatively quickly ${ }^{9}$. The speed of this degradation is impacted by oxygen availability, sample age and material which in turn impact upon the microbial community capable of carrying out decay ${ }^{10}$. Upon burial, particularly under anaerobic conditions, many fungal species (for example, soft rot fungi) typically involved in degradation cannot act. This means that the majority of degradation in anaerobic conditions is carried out by bacteria ${ }^{11}$. There is also evidence in marine sediments that key microbial communities, linked to anoxic environments can be central to increased preservation ${ }^{12}$. Ultimately, the mechanisms responsible for the excellent preservation observed at Vindolanda are unknown and will be explored within this study. Our assumption is that the exceptional levels of preservation seen at Vindolanda are brought about by a combination of environmental factors specifically linked to the unusual anaerobic and high iron conditions observed, through an interaction between local geochemistry, hydrology and past human activity at the site (clay sealing). Such conditions in turn impact on the microbial community within the soil, producing vivianite and limiting growth of degrading organisms.

The initial aim of this study was to characterise the microbial community within different occupation layers of archaeological soil at Vindolanda. Bacterial communities within the different occupation layers which exhibit various degrees of preservation were compared with non-occupation environmental soil layers. The overall aim was then to correlate changes in environmental variables within the site and begin to unpick whether the microorganisms, environmental conditions or a combination of the two may be responsible for the good preservation observed at Vindolanda. As the factors influencing preservation and decomposition are poorly understood it is hoped that this study will help to shape current thinking of factors responsible for improved preservation at archaeological sites, to allow strengthening of in-situ preservation techniques. To our knowledge, this is the first reported study of a Roman burial environment using both chemistry and microbiological data, obtained using next generation sequencing techniques. 


\section{Results}

\section{Environmental variables}

$\mathrm{pH}$ values were consistent between the soil locations (depth1p $(\mathrm{d} 1 \mathrm{p})=6.33 \pm 0.06$, depth2p $(\mathrm{d} 2 \mathrm{p})=6.35 \pm$ 0.20 , depth3i $(\mathrm{d} 3 \mathrm{i})=5.56 \pm 0.88$, depth $4 \mathrm{t}(\mathrm{d} 4 \mathrm{t})=6.40 \pm 0.16$, depth $5 \mathrm{c}(\mathrm{c} 1)=6.07 \pm 0.29$, depth6c $(\mathrm{c} 2)=$ $6.58 \pm 0.47)$. Kruskal-Wallis tests showed no significant difference in $\mathrm{pH}$ value $(\chi 2=46.38, d f=45, p=$ 0.42 ; supplementary date Fig. 1 ) between soil locations and significant differences in moisture content $(x 2=53, d f=17, p<0.001$; supplementary date Fig. 1$)$. Nemenyi tests showed that $d 1 p$ and $d 2 p$ had significantly more moisture than $\mathrm{c} 1$ and $\mathrm{c} 2$, but all other comparisons were not significantly different.

Elemental analysis obtained from pXRF analysis showed significant changes in elemental composition between the differing locations. D1p and d2p, the sites of best preservation, displayed different elemental composition with respect to phosphorus, sulphur and iron $(P<0.001)$. Pairwise comparisons using Dwass-Steele-Critchlow-Fligner (DSCF) showed that the interaction between phosphorus, sulphur and iron in $d 1 p$ and $d 2 p$ was not significantly different to each other, but were significantly different to d3i, d4t, c1 and c2. Elemental composition for major and minor elements are provided in Fig. 1. Phosphorus has a range of $\operatorname{Max}=1.094 ;$ Min $=0.512 ;$ Range $=0.582 ;$ Mean $=0.813 ;$ Median $=0.806$ in d1 $p$ and d2p.

\section{Microbial community profile}

There is a shift in the microbial community profile between the preservation samples at $d 1 p$ and $d 2 p$ and interface layer d3i when compared with other locations (Figure 2). Spearman's rank correlation analysis showed significant positive correlations with depth and Acidobacteria $\left(\rho=0.825, \mathrm{P}=2.52 \times 10^{-5}\right)$, Actinobacteria $\left(\rho=0.887, \mathrm{P}=9,189 \times 10^{-7}\right)$, Chloroflexi $\left(\rho=0.724, \mathrm{P}=6.78 \times 10^{-4}\right)$ and Planctomyces $(\rho=$ $\left.0.699, P=1.24 \times 10^{-3}\right)$ and negative correlations with Firmicutes $\left(\rho=-0.937, P=9.76 \times 10^{-9}\right)$, Bacteroidetes $\left(\rho=-0.687, P=1.65 \times 10^{-3}\right)$ and Spirochaetes $\left(\rho=-0.901, P=3.347 \times 10^{-7}\right)$. There was no significant correlation linking $\mathrm{pH}$ values to relative abundance of any phyla.

At OTU and genera level there were marked differences between the soil locations clearly separating samples from occupation layers with good preservation and interface samples from others (Figure 3). Specifically, identifiable dominating genera within preservation and interface layers were Sulfuricurvum, Flavobacterium and Methylophilus, with Ktedonobacter, Geobacter and Methylobacter dominating in nonpreservation layers. Although the composition of the community changes this was not reflected in a shift in diversity with both Shannon diversity and Evenness measures showing little difference between the locations: d1p H' $5.724 \pm 0.14$, Evenness $0.747 \pm 0.001$; d2p H' $6.340 \pm 0.12$, Evenness $0.773 \pm 0.006$; d3i $\mathrm{H}^{\prime} 5.286 \pm 0.10$, Evenness $0.688 \pm 0.011$, d4t H' $6.741 \pm 0.03$, Evenness $0.825 \pm 0.000 ; \mathrm{c} 1 \mathrm{H}^{\prime} 5.936 \pm 0.09$, Evenness $0.7778 \pm 0.002 ; \mathrm{c} 2 \mathrm{H}^{\prime} 6.120 \pm 0.09$, Evenness $0.779 \pm 0.009$.

\section{Microorganisms indicative of preservation layers}


LEfSe analysis of the microbial community revealed specific community structure associated with preservation layers characterised by Firmicutes, Epsilonproteobacteria, BRC1 and Chloroflexi with no phyla indicative of non-preservation layers due to varied communities. Tentative organisms which may be indicative of preservation layers are identified as: the Firmicute Turicibacter, AlphaproteobacteriaFilomicrobium and Sphingobium; Betaproteobacteria Pusillimonas and Vogesella; Epsilonproteobacteria Arcobacter; and Gammaproteobacteria Thiovirga (Figure 4)

\section{Composition of samples that contain vivianite.}

When compared with soils within $10 \mathrm{~cm}$, soils with vivianite formation showed comparable Shannon diversity (visible vivianite $=3.211 \pm 1.65$; no visible vivianite $=3.636 \pm 1.97$ ) and evenness (visible vivianite $=0.598 \pm 0.21$; no visible vivianite $=0.618 \pm 0.23$ ) at phyla level. Adjacent soils profiles were not dissimilar to the preservation layers shown in Figure 2 (Figure 5). However, sections with vivianite were dominated by a single genus ( $50.3 \%$ of the total OTU within one of the samples) Methylophilus compared with sections without $(P=0.0162)$ (Figure 5).

\section{Discussion}

\section{Elemental composition within the soil layers}

Overall, there were significant shifts in elemental composition between soil samples at Vindolanda specifically with increases in phosphorus, sulphur and iron within $\mathrm{d} 1 \mathrm{p}$ and $\mathrm{d} 2 \mathrm{p}$ preservation locations. Non-preservation locations $\mathrm{d} 3 \mathrm{i}, \mathrm{d} 4 \mathrm{t}, \mathrm{c} 1$ and $\mathrm{c} 2$ showed consistent elemental composition regardless of the different trench locations. Whilst preservation of artefacts is poor in $d 3 i$ and $d 4 t$ there is evidence of Roman occupation. However, there is no such evidence in c1 and c2 suggesting they sit outside of the settlement. Interestingly, there was little observable difference within $\mathrm{pH}$ values between any of the samples.

Iron and sulphate reduction, denitrification and nitrate respiration are associated with anaerobic environments ${ }^{13}$, with dissimilatory $\mathrm{Fe}^{3+}$ reduction being the most abundant anaerobic metabolism ${ }^{14}$. Anaerobic soil conditions are typically characterised by the accumulation of iron cations $\left(\mathrm{Fe}^{2+}\right.$ and $\left.\mathrm{Fe}^{3+}\right)$ as soil-available Fe is reduced. In aerobic conditions oxidation of $\mathrm{Fe}^{2+}$ to Fe seems to correlate to a speeding up of microbial metabolism and a decomposition of organic matter both within field and pot

experiments ${ }^{15}$. However, pXRF analysis used in the current study cannot differentiate between the different oxidative states of iron; it does however, suggest that there is an increase in the amount of iron present within these locations not just a change in redox state.

Phosphorus release is associated with increased iron reduction within anaerobic soil environments with the dynamics of phosphorus release and $\mathrm{Fe}^{3+}$ reduction closely linked ${ }^{16}$. However, there is also a relationship between the cycling of iron and phosphorus with the concentration of sulphate found within waterlogged environments. Within such conditions sulphate reduction results in increases in phosphorus 
release $^{17}$. The iron and phosphorus concentrations are higher at Vindolanda within locations showing preservation and could, therefore suggest why increased vivianite are observed here ${ }^{2}$. Ratios of less than 1.5 sulphur:iron are needed for vivianite formation within marine sediments ${ }^{18}$; all soils used within this study met these conditions. However, an excess of phosphorus is also needed which is only seen in $\mathrm{d} 1 \mathrm{p}$ and $d 2 p$.

Certain soil types are more likely to result in good archaeological preservation than others with anaerobic soils rich in organic material being more likely to show reduced biological oxidation of wood, leather and soft tissue ${ }^{19}$, partly due to the microorganism which flourish in such environments ${ }^{10}$. Reduced forms of phosphorus, sulphur and iron are more likely to be found within anaerobic soils compared with aerobic. Furthermore, the changes in moisture conditions at Vindolanda are linked to the periodic release of agricultural leachate which would be expected to increase soil degradation but may allow reaction with organic material within the soil, thus facilitating a natural 'tanning' process ${ }^{19}$.

\section{The Microbial community within the Vindolanda soil layers}

Preservation and interface locations $\mathrm{d} 1 \mathrm{p}, \mathrm{d} 2 \mathrm{p}$ and $\mathrm{d} 3 \mathrm{i}$ are distinct from other samples in terms of composition of phyla and genera. Shifts in bacterial phyla are correlated to location of sample but not $\mathrm{pH}$ values or elemental composition. Preservation locations are dominated by Firmicutes, Bacteroidetes and Proteobacteria at a phylum level with LEfSe analysis suggesting that Firmicutes, Epsilonproteobacteria, $B R C 1$ and Chloroflexi may be indicative of preservation. Non-preservation and control locations were typified by increased abundance of Acidobacteria, Actinobacteria and Planctomycetes. Shannon diversity remained high within preservation layers and was comparable to the surrounding soil. Maintenance of diversity and evenness within good archaeological preserving environments has been shown previously in No. 1 Wangshanqiao Chu Tomb in Jingzhou, China ${ }^{20}$.

Previous studies have shown that at the phylum level soils within the top approximately $20 \mathrm{~cm}$ are likely to be dominated by Acidobacteria, Actinobacteria and Alphaproteobacteria with Firmicutes and Spirochaetes being more abundant below $50 \mathrm{~cm}^{21}$. Acidobacteria and Actinobacteria are increased within $\mathrm{d} 4 \mathrm{t}, \mathrm{c} 1$ and $\mathrm{c} 2$ compared with $\mathrm{d} 1 \mathrm{p}, \mathrm{d} 2 \mathrm{p}$ and d3i. Actinobacteria are widely recognised as being crucial to aerobic degradation of organic matter particularly that which is cellulose based ${ }^{22,23}$. Acidobacteria are a diverse phylum which are mostly heterotrophic in metabolism and can degrade a wide range of carbohydrate sources ${ }^{24}$. Members of the Acidobacteria group 1-4 have been linked with degradation of cellulose based material ${ }^{25}$ and are seen in significant abundance within layers $4-6$ of this study. Interestingly they are greatly reduced within the preservation layers despite the $\mathrm{pH}$ values remaining consistent. This is probably due to the anaerobic conditions present within these layers as the majority of Acidobacteria are aerobic ${ }^{24}$.

Firmicutes, Bacteroidetes and Proteobacteria were significantly increased within the preservation layers. However, this is most likely a result of the anaerobic conditions found rather than these phyla not being 
decomposers. Proteobacteria, Firmicutes and Bacteroidetes are the most dominant phyla in solid waste decomposition within anaerobic phases ${ }^{26}$ with Firmicutes and Bacteroidetes proposed as the main microorganisms involved in cellulose degradation ${ }^{25}$. There are very few studies assessing microbiology within archaeological sites. However, those available correspond with our findings of consistent microbial diversity between layers which show preservation and those which do not ${ }^{20,27}$. Siles (2018) also found varied soil profiles that were common to soil environments and recorded no dominant 'rare' microbial taxa as clear indicators of preservation ${ }^{27}$.

At the genus level preservation locations showed increased abundance of Sulficurvum, Flavobacterium and Methylophilus with additional genera Turicibacter, Filomicrobium, Sphingobium, Pusillimonas, Vogesella, Arcobacter and Thiovirga being identified as indicative of preservation by LEfSe. These microorganisms are not typically indicative of depth or oxygen availability as changes at phylum level were. Instead Sulficurvum, Flavobacterium and Methylophilus are all capable of degrading polycyclic aromatic hydrocarbons (PAHs) and are found to be encouraged by increased concentrations of iron and sulphur ${ }^{28,29}$. Flavobacterium and Methylophilus are aerobic, whilst Sulfuricurvum are facultative anaerobes which are major contributors to the sulphur cycle given their abilities to oxidise sulphur and are observed in the presence of excess methane ${ }^{30-32}$. This coupled with the changes in soil chemistry involved suggests an unusual soil environment within the preservation layers at Vindolanda.

\section{Microbial community with vivianite}

Interestingly, further investigation of samples with visible vivianite showed that these soils contained marked increases in Methylophilus compared with adjacent soils. Methylophilus are methylotrophic Betaproteobacteria commonly occurring in activated sludge, mud, and aquatic habitats, and are capable

of utilizing methanol or methylamine as a sole source of carbon and energy ${ }^{33}$. Members of the genus are thought to be strictly aerobic and have been extracted from various soils ${ }^{32}$. Usually Methylophilus would be expected to be found in low abundance within soil environments. However, previous studies have found increased amounts of $\mathrm{CO}_{2}$ within soil samples can lead to proliferation of Methylophilus presumably due to an increased abundance of methane ${ }^{34}$.

Methylophilus is capable of solubilizing inorganic phosphorus ${ }^{35}$ and produces siderophores and indole acetic acid ${ }^{32}$. Studies have shown that Methylophilus species are capable of reducing iron species such as ferrihydrite within conditions of increased methanol with evidence that the ferrihydrite was transformed into crystalline magnetite, a mixed $\mathrm{Fe}^{3+}$ oxide $^{35}$. Furthermore, other microorganisms capable of producing magnetite can also produce vivianite in phosphate rich environments ${ }^{36}$.

Studies in Brazil have shown that, with the exception of environments that are high in sulphur, phosphorus and iron the production of iron species such as magnetite and haematite are relatively common while the production of vivianite is more restricted ${ }^{37}$. These conditions are similar to those we have identified within the preservation layers at Vindolanda. Additionally, analysis within the South China Sea showed that concentrations of iron-bound phosphorus and organic-phosphorus were influenced by 
sulfate-driven and metal-driven anaerobic oxidation of methane resulting in the release of phosphates and $\mathrm{Fe}^{2+}$ and a subsequent significantly increased formation of vivianite ${ }^{38}$.

\section{Conclusion}

Our findings taken together suggest that the soil at Vindolanda contains distinctive chemical and microbial profiles associated with layers that show increased preservation of organic/inorganic artefacts. These shifts are not simply the result of changes in depth and oxygen availability but suggest that the specific conditions potentially allow the microbial production of vivianite which may lead to enhanced preservation of artefacts. The role of the occupation layers as phosphorus sinks is strongly linked to the abundance of vivanite. More research is needed to clearly link the presence of Methylophilus with vivianite production.

\section{Methods}

\section{Sampling and archaeological context}

Soil was sampled from two trenches within the Vindolanda site $\left(54.9911^{\circ} \mathrm{N} 2.3608^{\circ} \mathrm{W}\right)$. The external surface was scraped back by approximately $5 \mathrm{~cm}$. Samples were then taken in triplicate at four equal depths ( $d 1 p, d 2 p, d 3 i$ and $d 4 t)$, each representing a separate archaeological context (see supplementary Fig. 2). The top $40 \mathrm{~cm}$ of the trench had was exposed for approximately 3 months prior to the sampling taking place down to the interface level of $d 4 t$. The lower $1 \mathrm{~m}$ section was excavated to the level of $\mathrm{d} 1 \mathrm{p}$ four weeks prior to the sampling taking place. D1p and $d 2 p$ correlate to the deepest layers and are associated with the best quality preservation. D3i and D4t are associated with lower quality preservation while d3i forming an interface (i) layer. Soil was sampled in triplicate (A-B) from a control (c) trench showing no evidence occupation or archaeological preservation, at two depths (c1-c2) (see supplementary Fig. 3).

In addition, further samples were taken from a rampart section, as detailed in Taylor et a/2019. The rampart sample was sampled in triplicate from the vivianite visible layer (blue) as well as triplicate samples within $10 \mathrm{~cm}$ which showed no visible vivianite formation.

\section{Moisture}

Triplicate soils were weighed before and after drying in an oven overnight at $105^{\circ} \mathrm{C}$ to determine the moisture content of the original sample using Eq. 1.

Equation 1: wet weight $(g)-d r y$ weight $(g) / d r y$ weight $(g) \times 100=$ moisture content $\%$

\section{$\mathrm{pH}$}

Dried soils $(10 \mathrm{~g})$ were placed into plastic cups with distilled water added $(20 \mathrm{ml})$ for a 1:2 proportion. The solution was stirred with a glass rod and settled for 30 minutes. $\mathrm{pH}$ values was analysed using an 
Advanced Jenway $3510 \mathrm{pH}$ meter calibrated with commercial buffers of $\mathrm{pH} \mathrm{4,7}$ and 10 . The electrode probe was rinsed between each sample.

\section{pXRF}

Soils were analysed following the method provided by Williams $(2020)^{39}$. The dried soil samples were homogenised with mortar and pestle for 140 seconds and sieved to $2 \mathrm{~mm}$. Soil were loaded into XRF sample cups (SPEX CertiPrep ${ }^{\text {TM }} 3529$ ) and covered with $5 \mu$ m polypropylene thin-film (SPEX ${ }^{\text {TM }}$ SamplePrep 3520 window film). A Thermo Niton ${ }^{\mathrm{TM}} \mathrm{XL3t}$ GOLDD + pXRF with an Ag anode (6-50kV, 0-200 $\mu \mathrm{A}$ max X-ray tube) was used to analyse the soil. The pXRF was warmed up, system checked against the internal $1 \frac{1 / 4}{4}$ $\mathrm{Cr}-1 / 2$ Mo coupon, and scanned against a blank standard and NIST 2709a standard $(y=0.9674 x-0.0089$, $\left.r^{2}=0.9998\right)$. The NIST 2709a is a San Joaquin soil, used because it was certified for most elements of interest within the single calibration sample. The pXRF was periodically reset and system checked to account for drift. Soil samples were analysed using Mining mode (fundamental parameters), with 30second scans for the main filter $(50 \mathrm{kV}, \leq 50 \mu \mathrm{A})$, low filter $(20 \mathrm{kV}, \leq 100 \mu \mathrm{A})$ and high filter $(50 \mathrm{kV}, \leq 40$ $\mu \mathrm{A})$, and a 60 -second scan for the light filter $(6 \mathrm{kV}, \leq 200 \mu \mathrm{A})$.

\section{DNA extraction}

DNA was extracted from $0.25 \mathrm{~g}$ of each soil sample using the Qiagen DNeasy PowerSoil Kit following manufacturer's instructions. DNA quality and yield were measured using NanoDrop 1000 spectrophotometer (V3.8.1, ThermoFisher) and agarose gel electrophoresis. DNA was stored at $-80^{\circ} \mathrm{C}$ prior to further analysis.

\section{Next Generation Sequencing}

Bacterial community DNA sequencing was made (NU-OMICs, Northumbria University, Newcastle Upon Tyne, U.K.) by targeting the V4 region of the 16S rRNA gene according to Kozich (2013) ${ }^{40}$. The raw sequencing reads were processed in FASTQ format and analysed with Mothur software package (version 1.36.1) (University of Michigan, U.S.A.). UCHIME was used to quality check and filter the FASTA formatted sequences for chimeras. These were aligned to the SILVA reference, and taxonomic identification of the reads was assessed by assigning sequences to operational taxonomic units (OTUs) using Ribosomal Database Project (RDP) classification. PCR negative controls were run and sequenced in parallel to the experimental samples. The OTUs recorded in negative controls and samples were excluded from further analysis. Non-bacterial sequences (Archaea/Eukaryota/Unclassified) were discarded. OTUs less than 3\% were classified as rare taxa with these and the unclassified OTUs omitted from the plots.

\section{Statistical analysis}

Data were analysed in R 4.0.2 $2^{41}$ using the car, DescTools and PMCMR packages ${ }^{42-44}$. Normality and variance failed the Q-Q plot, Shapiro-Wilk's and Levene's assumption tests. Data were analysed using Kruskal-Wallis rank sum tests, followed by Nemenyi tests with Chi-Square distribution to identify 
significant differences between burial layers. Tukey box plots of the median and quartiles were produced using the ggplot2 package ${ }^{45}$ to show the change in raw elemental concentration with increasing burial depth. The tidypaleo package in tidyverse ${ }^{46}$ was used to produce stratigraphic plots of the moisture content and $\mathrm{pH}$ values against burial depth.

Operational taxonomic unit (OUT) tables and metadata were analysed using R version 4.0.2. Samples were faceted to rarefy, relative abundance data was compiled and most abundant phyla and genera were sought. Within the readr package ${ }^{47}$ significant differences were identified using ANOVA and TukeyHSD tests and Spearman Correlation was used to determine significant correlation between variables. Figures were created using gplots ${ }^{48}$. Taxa indicative of preservation were identified, and histograms generated following Linear Discriminant Analysis Effect Size (LEfSe) analysis completed in Galaxy ${ }^{49}$.

\section{Declarations}

\section{Acknowledgements}

The authors thank Dr Andrew Birley and the Vindolanda Trust for providing access to the archaeological samples. There are no conflicts of interest to declare. The data that support the findings of this study are available in the additional supporting information.

\section{Author contributions}

GT and $\mathrm{CO}$ wrote the first draft of the manuscript and participated in sample collection and data analysis. $\mathrm{RW}$ and $\mathrm{HH}$ prepared and analysed the pXRF samples. AN organized and conducted the Next Generation Sequencing. $A B$ and $E G$ was involved in the fieldwork and sample collection. TKR sample preparation for Next generation sequencing.

\section{References}

1. Birley, R. Vindolanda: A Roman frontier post on Hadrian's Wall (Thames and Hudson, London, 1977).

2. Taylor, G., Hefford, R. J. W., Birley, A. \& Huntley, J. P. Identifying the "blue substance" at the Roman site of Vindolanda, Northumberland. Journal of Archaeological Science: Reports. 24, 582-587 (2019).

3. Holden, J. et al. Hydrological controls of in situ preservation of waterlogged archaeological deposits. Earth-Science Reviews. 78 (1-2), 59-83 (2006).

4. Caple, C. Reburial of waterlogged wood, the problems and potential of this conservation technique. International Biodeterioration and Biodegradation. 34 (1), 61-72 (1994).

5. McGowan, G. \& Prangnell, J. The significance of vivianite in archaeological settings. Geoarchaeology. 21 (1), 93-111 (2006). 
6. Sánchez-Román, M., Puente-Sánchez, F., Parro, V. \& Amils, R. Nucleation of Fe-rich phosphates and carbonates on microbial cells and exopolymeric substances. Frontiers in Microbiology. 2015;6(SEP).

7. Miot, J. et al. Transformation of vivianite by anaerobic nitrate-reducing iron-oxidizing bacteria. Geobiology. 7 (3), 373-384 (2009).

8. Volkland, H. P. et al. Bacterial phosphating of mild (unalloyed) steel. Applied and Environmental Microbiology. 66 (10), 4389-4395 (2000).

9. Blanchette, R. A., Nilsson, T., Daniel, G. \& Abad, A. Biological degradation of wood.American Chemical Society.1990:141-174.

10. Björdal, C. G., Nilsson, T. \& Daniel, G. Microbial decay of waterlogged archaeological wood found in Sweden. Applicable to archaeology and conservation. International Biodeterioration and Biodegradation. 43 (1-2), 63-73 (1999).

11. Björdal, C. G. Microbial degradation of waterlogged archaeological wood. Journal of Cultural Heritage. 13 (3 SUPPL.), S118-S122 (2012).

12. Jessen, G. L. et al. Hypoxia causes preservation of labile organic matter and changes seafloor microbial community composition (Black Sea).Sci Adv.2017;3(2).

13. Tiedje, J. M., Sexstone, A. J., Parkin, T. B. \& Revsbech, N. P. Anaerobic processes in soil. Plant and Soil. 76 (1-3), 197-212 (1984).

14. Keiluweit, M., Wanzek, T., Kleber, M., Nico, P. \& Fendorf, S. Anaerobic microsites have an unaccounted role in soil carbon stabilization. Nat Commun.2017;8(1).

15. Hall, S. J. \& Silver, W. L. Iron oxidation stimulates organic matter decomposition in humid tropical forest soils. Global Change Biol. 19 (9), 2804-2813 (2013).

16. Forsmann, D. M. \& Kjaergaard, C. Phosphorus release from anaerobic peat soils during convective discharge - Effect of soil Fe: P molar ratio and preferential flow. Geoderma. 223-225 (1), 21-32 (2014).

17. Lehtoranta, J., Ekholm, P., Wahlström, S., Tallberg, P. \& Uusitalo, R. Labile organic carbon regulates phosphorus release from eroded soil transported into anaerobic coastal systems. Ambio. 44 (2), 263-273 (2015).

18. Rothe, M., Kleeberg, A. \& Hupfer, M. The occurrence, identification and environmental relevance of vivianite in waterlogged soils and aquatic sediments. Earth-Science Reviews. 158, 51-64 (2016).

19. Kibblewhite, M., Tóth, G. \& Hermann, T. Predicting the preservation of cultural artefacts and buried materials in soil. Science of the Total Environment. 529, 249-263 (2015).

20. Xu, J., Wei, Y., Jia, H., Xiao, L. \& Gong, D. A new perspective on studying burial environment before archaeological excavation: Analyzing bacterial community distribution by high-throughput sequencing. Scientific Reports.2017;7.

21. Douterelo, I., Goulder, R. \& Lillie, M. Soil microbial community response to land-management and depth, related to the degradation of organic matter in English wetlands: Implications for the in situ preservation of archaeological remains. App/ Soil Ecol. 44 (3), 219-227 (2010). 
22. Wang, C. et al. Metagenomic analysis of microbial consortia enriched from compost: New insights into the role of Actinobacteria in lignocellulose decomposition.Biotechnol Biofuels.2016;9(1).

23. Pankratov, T. A., Dedysh, S. N. \& Zavarzin, G. A. The leading role of actinobacteria in aerobic cellulose degradation in Sphagnum peat bogs. Dokl Biol Sci. 410 (1), 428-430 (2006).

24. Kielak, A. M., Barreto, C. C., Kowalchuk, G. A., van Veen, J. A. \& Kuramae, E. E. The ecology of Acidobacteria: Moving beyond genes and genomes. Frontiers in Microbiology. 2016;7(MAY).

25. Eichorst, S. A., Kuske, C. R. \& Schmidt, T. M. Influence of plant polymers on the distribution and cultivation of bacteria in the phylum acidobacteria. Applied and Environmental Microbiology. 77 (2), 586-596 (2011).

26. Yang, S. \& Song, L. Succession of bacterial community structure and metabolic function during solid waste decomposition.Bioresource Technology.2019;291.

27. Siles, J. A., Öhlinger, B., Cajthaml, T., Kistler, E. \& Margesin, R. Characterization of soil bacterial, archaeal and fungal communities inhabiting archaeological human-impacted layers at Monte lato settlement (Sicily, Italy).Scientific Reports.2018;8(1).

28. Sun, W. et al. Profiling microbial community in a watershed heavily contaminated by an active antimony (Sb) mine in Southwest China. Science of the Total Environment. 550, 297-308 (2016).

29. Haaijer, S. C. M. et al. Bacteria associated with iron seeps in a sulfur-rich, neutral pH, freshwater ecosystem. ISME Journal. 2 (12), 1231-1242 (2008).

30. Li, X. et al. Metagenome-assembled genome sequence of sulfuricurvum sp. strain IAE1, isolated from a 4-chlorophenol-degrading consortium. Micro Res Ann.2019;8(31).

31. Hubert, C. R. J. et al. Massive dominance of Epsilonproteobacteria in formation waters from a Canadian oil sands reservoir containing severely biodegraded oil. Environmental Microbiology. 14 (2), 387-404 (2012).

32. Madhaiyan, M., Poonguzhali, S., Kwon, S. W. \& Sa, T. M. Methylophilus rhizosphaerae sp. nov., a restricted facultative methylotroph isolated from rice rhizosphere soil. Int J Syst Evol Microbiol. 59 (11), 2904-2908 (2009).

33. Doronina, N., Kaparullina, E. \& Trotsenko, Y.. The Family Methylophilaceae. In: Rosenberg E, DeLong EF, Lory S, Stackebrandt E, Thompson F, eds. The Prokaryotes: Alphaproteobacteria and Betaproteobacteria. Berlin, Heidelberg:Springer Berlin Heidelberg; 2014:869-880.

34. Ma, J. et al. Short-term effects of $\mathrm{CO} 2$ leakage on the soil bacterial community in a simulated gas leakage scenario. PeerJ. 2017, 11 (2017).

35. Yang, Y. et al. Extracellular electron transfer of Methylophilus methylotrophs. Process Biochem. 94, 313-318 (2020).

36. Veeramani, $\mathrm{H}$. et al. Products of abiotic $\mathrm{U}(\mathrm{VI})$ reduction by biogenic magnetite and vivianite. Geochimica et Cosmochimica Acta. 75 (9), 2512-2528 (2011).

37. Volpato, J. Relation between geochemistry and minerals (magnetite, hematite, pyrite and vivianite) in contamineted estuarine sediments, Santos, Sao Paulo, Brazil., Universidade Estadual de Campinas; 
2015.

38. Wu, D. et al. Zone of metal-driven anaerobic oxidation of methane is an important sink for phosphorus in the Taixinan Basin, South China Sea. Marine Geology. 427, 1-10 (2020).

39. Williams, R., Taylor, G. \& Orr, C. pXRF method development for elemental analysis of archaeological soil. Archaeometry. 62 (6), 1145-1163 (2020).

40. Kozich, J., Westcott, S. L., Baxter, N. T., Highlander, S. K. \& Schloss, P. D. Development of a dual-index sequencing strategy and curation pipeline for analyzing amplicon sequence data on the miseq illumina sequencing platform. Applied and Environmental Microbiology. 79 (17), 5112-5120 (2013).

41. R: A language and environment for statistical computing [computer program]. Vienna:R Foundation for Statistical Computing; 2020.

42. Signorell, A. DescTools: Tools for descriptive statistics. 2016.

43. Pohlert, T. The pairwise multiple comparison of mean ranks package (PMCMR). 2015.

44. Fox, J. \& Weisberg, S. An $\{R\}$ companion to applied regression. 2011.

45. Wickham, H. ggplot2: Elegant graphics for data analysis. 2016.

46. Wickham, H. et al. Welcome to the Tidyverse. The journal of open source software. 4 (43), 1686 (2019).

47. Wickham, H., Hester, J. \& Francois, R. readr: read rectangular Text Data. R package version 1.3.1.. 2018; https://CRAN.R-project.org/package=readr.

48. Warnes, G. et al. L, Gplots:Various R Programming Tools for Plotting Data. R package 3.03.. 2020; https://CRAN.R-project.org/package=gplots.

49. Segata, N. et al. Metagenomic biomarker discovery and explanation.Genome Biol.2011;12(6).

\section{Figures}



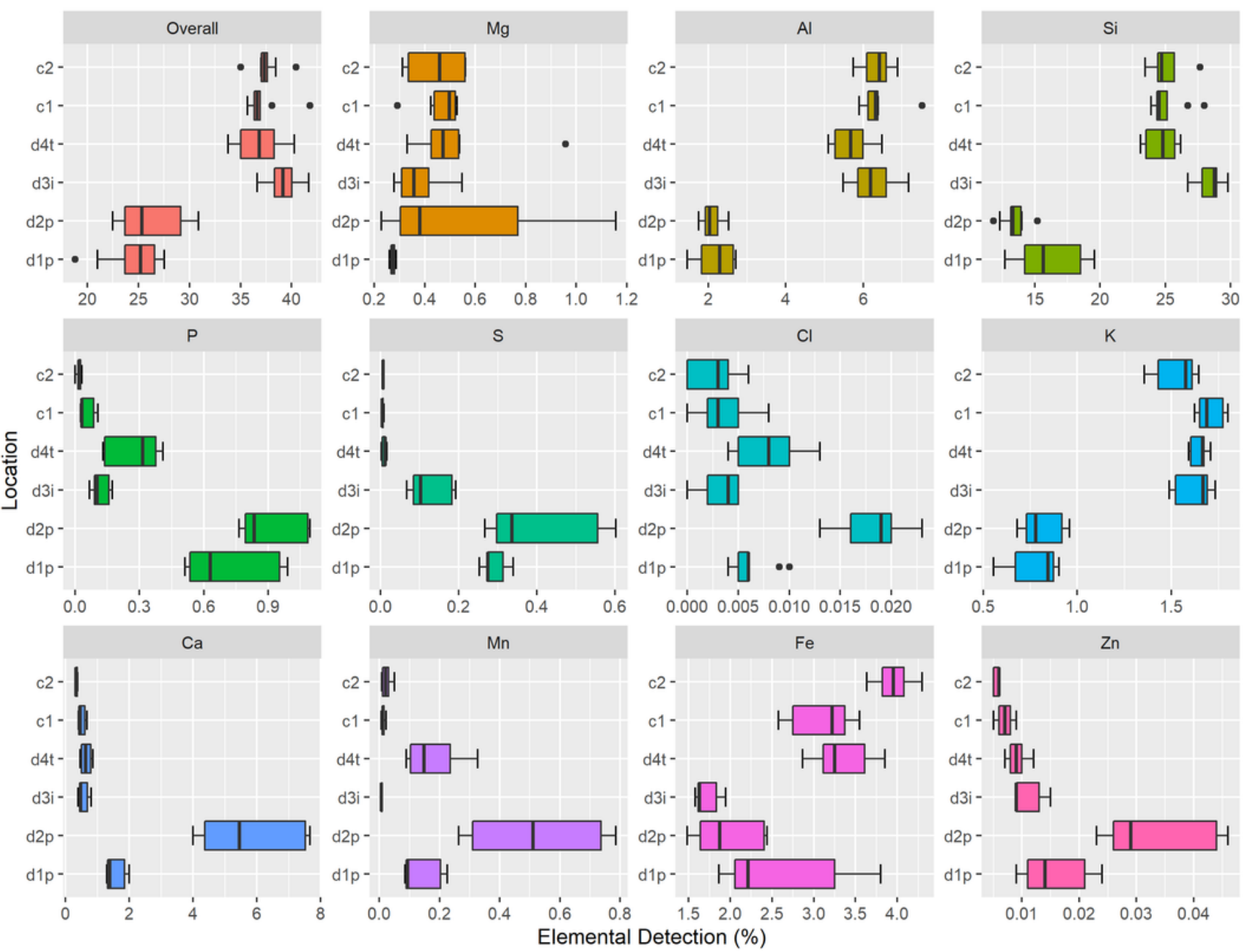

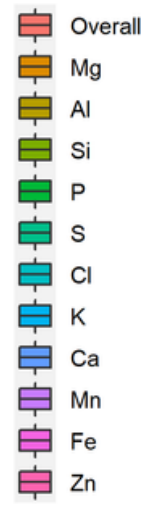

Figure 1

Elemental analysis for minor and major elements from sample d1p, d2p, d3i, d4t, c1 and c2. 


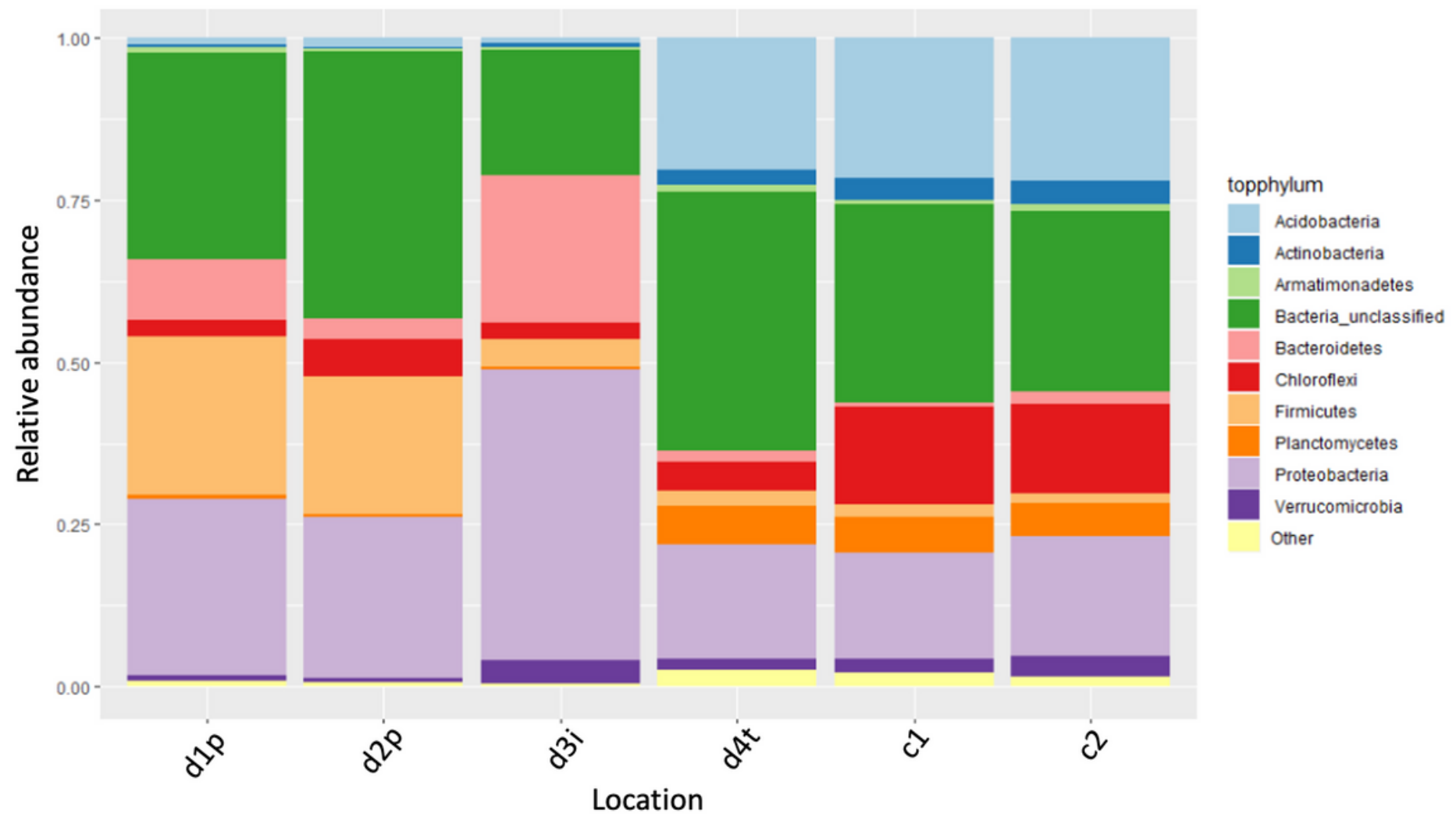

Figure 2

Relative abundance of bacterial phyla across six locations of the study. Replicates are averaged. The ten most abundant phyla are shown with the remainder shown as 'other'

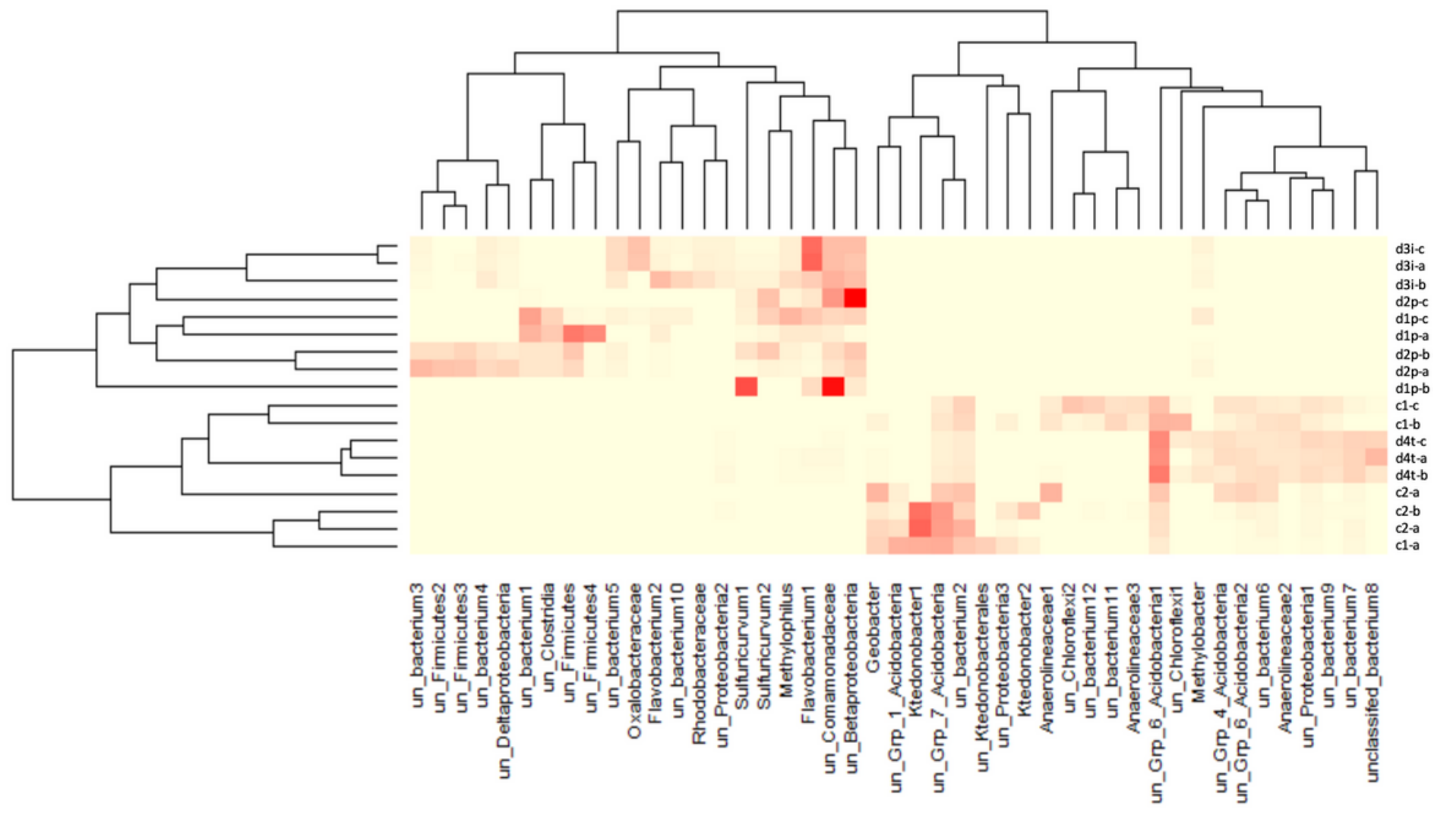




\section{Figure 3}

Heatmap showing the distribution of OTU within each replicate sample. Replicate samples are shown with $-a,-b$ and $-c$. Data is simplified so that OTU are only depicted if they contribute more than $1 \%$ of a single sample. Dark red $=1$, pale yellow $=0$. Within OTU names 'un' = unclassified.
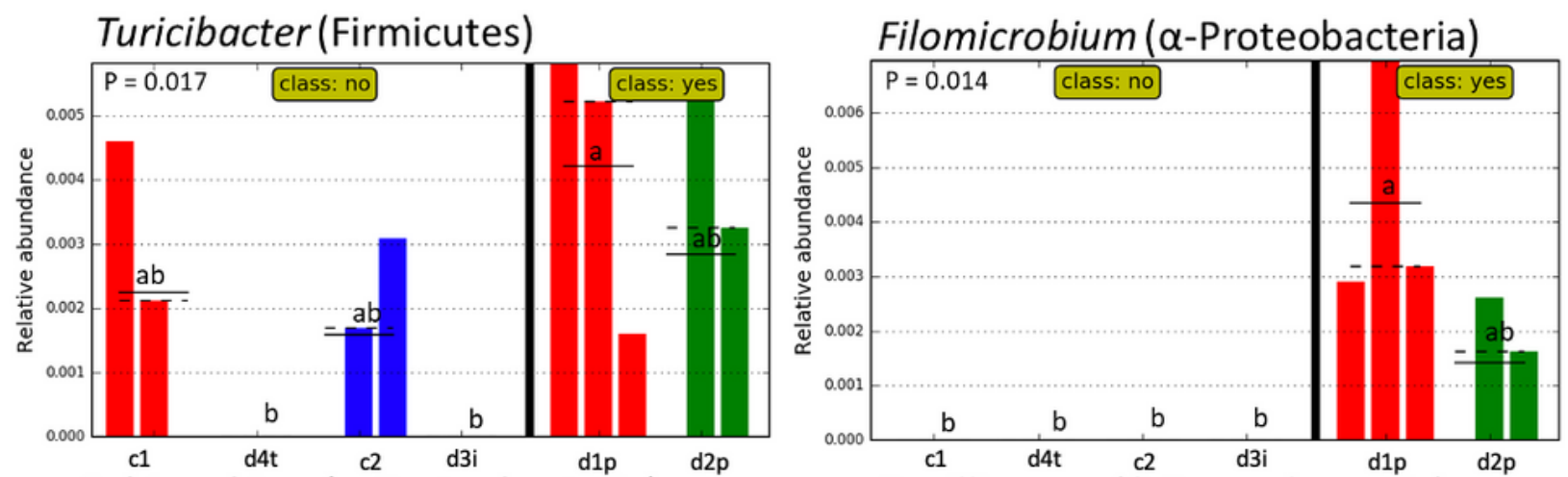

Sphingobium ( $\alpha$-Proteobacteria)

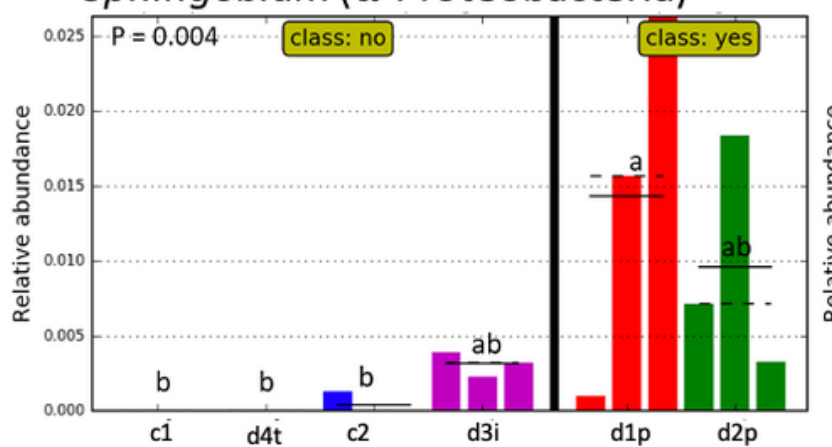

Pusillimonas ( $\beta$-Proteobacteria)

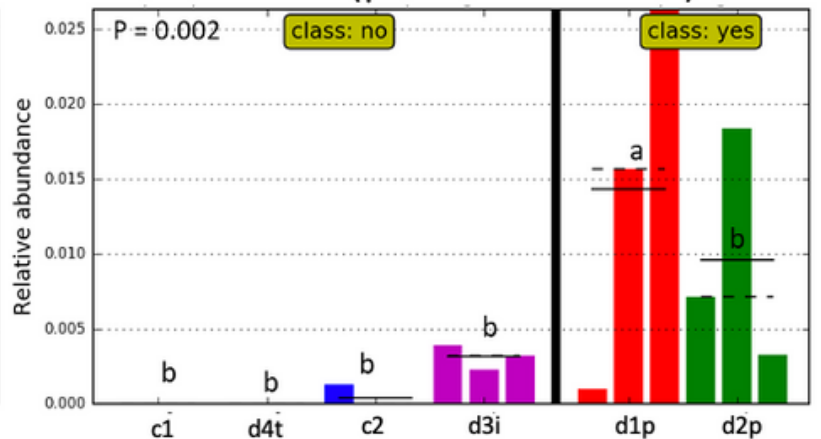

Vogesella ( $\beta$-Proteobacteria)

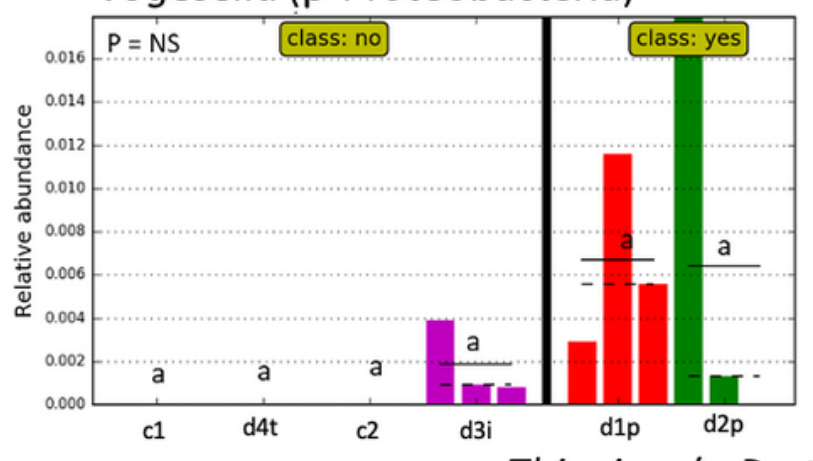

$\operatorname{Arcobacter}(\varepsilon-$ Proteobacteria)

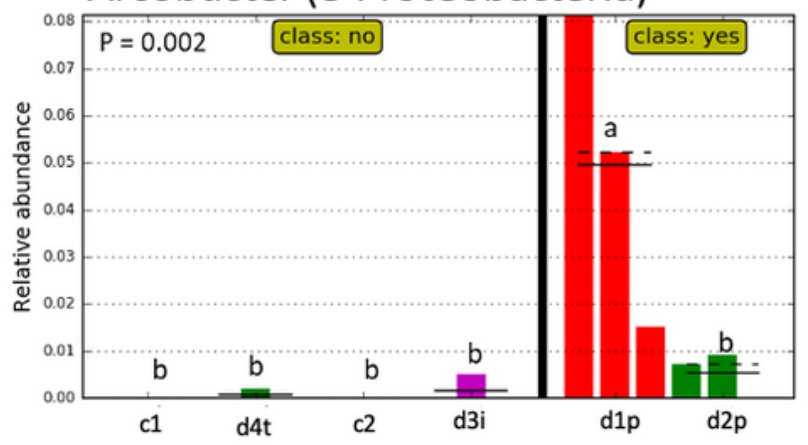

Thiovirga ( $\gamma$-Proteobacteria)

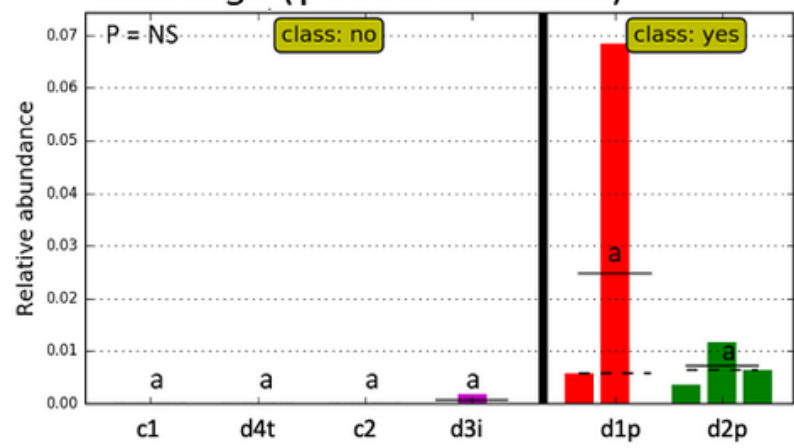

Figure 4 
Histograms generated following LEfSe analysis showing relative abundance of genera identified as potentially indicative of preservation locations. Class shows if samples are within a preservation location. $P$ values are listed in corner of each figure. NS = non-significant. Tukey's test within each graph is represented by letters. Layers which share letters are not significantly different from each other.
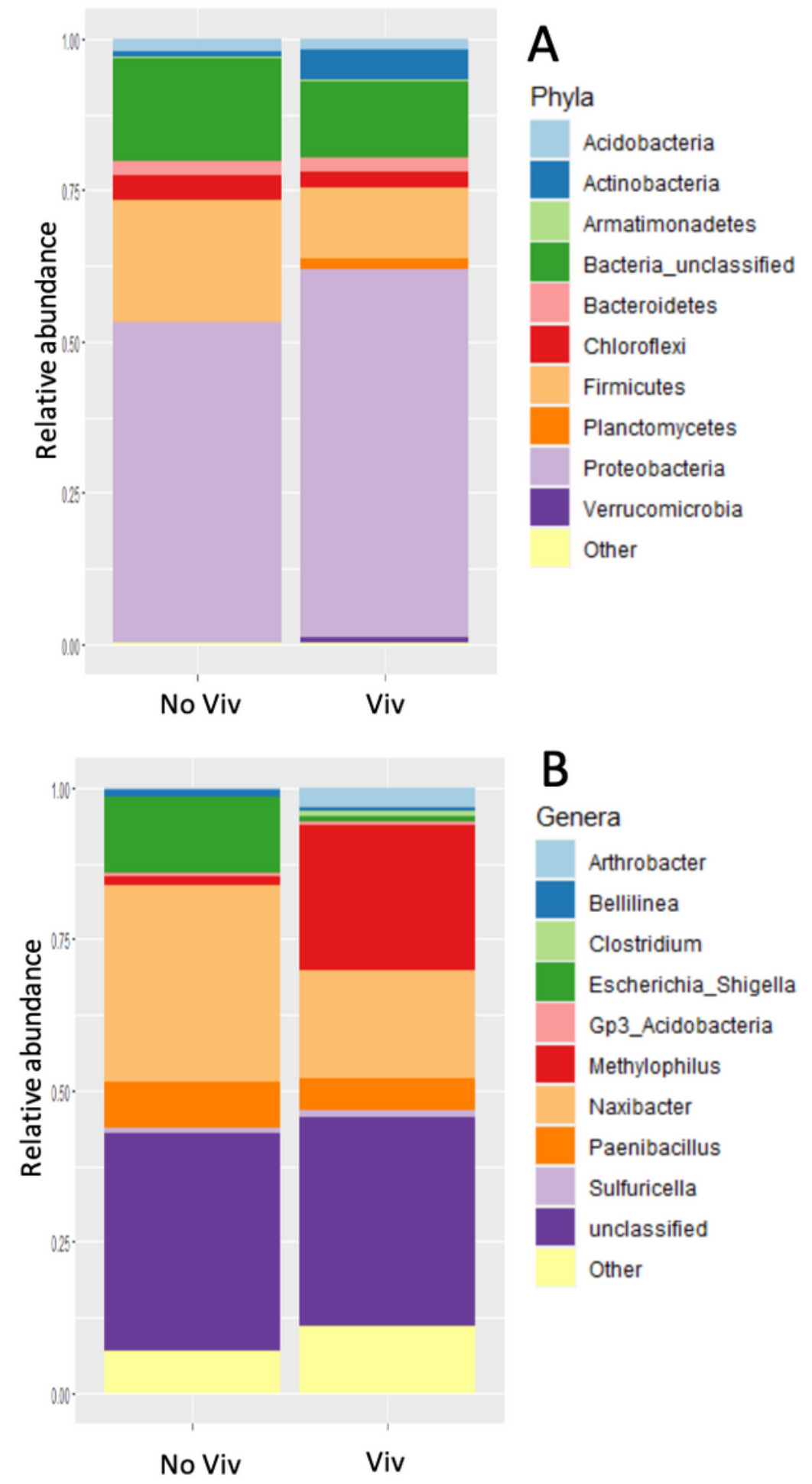

Figure 5 
Relative abundance of bacterial phyla (A) and genera (B) within samples showing visible vivianite (Viv) or no visible vivianite (No Viv). Replicates are averaged. The ten most abundant phyla/genera are shown with the remainder shown as 'other'

\section{Supplementary Files}

This is a list of supplementary files associated with this preprint. Click to download.

- TaylorSupplentaryFigureFINAL.docx 